\title{
Polymerization of Methyl Methacrylate Initiated by Benzoin-Pyridine-Carbon Tetrachloride System. Substituent and Solvent Effects
}

\author{
Kenzo Inoue, ${ }^{*}$ Kazunori Mochizuki, ${ }^{* *}$ and Teiichi Tanigaki** \\ *Department of Industrial Chemistry, Niihama Technical College, \\ Niihama, Ehime 792, Japan. \\ **Department of Industrial Chemistry, Faculty of Engineering, \\ Ehime University, Matsuyama 790, Japan.
}

(Received November 10, 1976)

\begin{abstract}
The polymerization of methyl methacrylate (MMA) by substituted benzoin-pyridine-carbon tetrachloride system was carried out at $60^{\circ} \mathrm{C}$. The electronwithdrawing substituent in benzoin accelerated the rate of polymerization, whereas the electron-donating groups decelerated it. Hammett plots gave a straight line with a $\rho$ of 0.56 . The rate of polymerization increased with an increase in the basicity of the amine but depended strongly on the steric effect. The effect of solvents on the rate of polymerization was found to be remarkable. On the basis of these results, the mechanism of initiation was discussed.
\end{abstract}

KEY WORDS Benzoin / Amine / Carbon Tetrachloride / Radical Polymerization / Methyl Methacrylate / Enediol / Solvent Effect / Donor Number / Charge-Transfer Complex /

The polymerization of vinyl monomer in the presence of amine and haloalkanes has been reported by many authors, and the effects of metal salts on the initiation reaction have been investigated. ${ }^{1}$ For example, Takemoto, et al., ${ }^{2,3}$ have reported that the polymerization of vinyl monomer with $\mathrm{Cu}(\mathrm{II})$ complex-amine-carbon tetrachloride system is initiated by the trichloromethyl radical formed by the reaction of the amine radical with carbon tetrachloride. On the other hand, Smith, et al.,${ }^{4}$ have shown that amine reacts with carbon tetrachloride in the presence of $\mathrm{Cu}(\mathrm{II})$ to give the trichloromethyl radical. The presence of reducing agents is felt to be important for the formation of trichloromethyl radical in these reactions. Benzoin has been used as an effective reducing agent in the initiator system for polymerization. ${ }^{5}$

In our previous paper, ${ }^{6}$ we reported that the polymerization of methyl methacrylate (MMA) with benzoin-pyridine-carbon tetrachloride system proceeds via a charge-transfer complex between pyridine and carbon tetrachloride, and then the primary radical, i.e., trichloromethyl radical, is produced by the interaction between benzoin and the complex. In order to confirm this mechanism, we examined the effects of the substituents in benzoin and pyridine and of the solvent on the rate of polymerization of MMA with substituted benzoin (subBN) or substituted pyridine (subPy) as one component of the initiator system.

\section{EXPERIMENTAL}

\section{Materials}

4-Methoxy, 4,4'-dimethoxy, 4,4'-dimethyl, 4dimethylamino, 4-dimethylamino- $4^{\prime}$-chloro, and $4,4^{\prime}$-dichloro derivatives of benzoin were prepared by the usual benzoin condensation. $\alpha$ Phenylbenzoin was prepared from benzil and phenyl magnesium bromide. All of these compounds were purified by recrystallization. The following reagents were used as the substituted pyridine: $\alpha$-picoline, $\beta$-picoline, $\gamma$-picoline, 2,4 lutidine, 2,6-lutidine, and 2,4,6-collidine. These reagents were purified by the distillation. The other reagents used in this study were purified 
by the usual methods.

The polymerization method was described in the previous paper. $^{6}$

\section{RESULTS}

Substituted Benzoins. The simple initiator, sub$\mathrm{BN}$ only, or the subBN-CCl${ }_{4}$ system has less effect for initiating the polymerization of MMA. In the subBN-Py system some effect was evident in the rate of polymerization, as shown in Table I. However the tendency to increase the rate was merely shown for the benzoin with the electron-donating substituents. No relationship between the substituents and the rate of polymerization was observed quantitatively, because of the smaller effect in this initiator system. The overall rate of polymerization initiated by subBN-Py- $\mathrm{CCl}_{4}$ system was faster than that by the other initiator systems. In the case of the polymerization initiated simultaneously by many initiator systems, the square of the overall rate of polymerization is shown to be the sum of the squares of the rate by each system. In the polymerization of MMA by the subBN-Py- $\mathrm{CCl}_{4}$ system, the polymerization by the other initiator systems such as subBN-Py or subBN was thought to occur simultaneously. The rate of polymerization by the subBN-Py- $\mathrm{CCl}_{4}$ system was calculated from the overall rate and the rate by other systems using the above relation. The electron-withdrawing substituent accelerates the rate of polymerization by the subBN-Py- $\mathrm{CCl}_{4}$

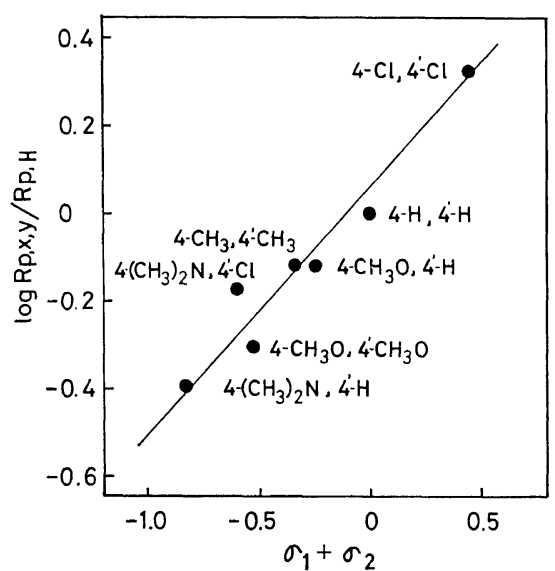

Figure 1. Relationship between $\log R_{\mathrm{p}, \mathrm{x}, \mathrm{y}} / \boldsymbol{R}_{\mathrm{p}, \mathrm{H}}$ and the sum of Hammett's $\sigma$ values: Reaction condition, see Table 1 .

system, whereas the electron-donating group decelerates it. The relationship between the relative rate of polymerization with three-component system and the sum of corresponding Hammett's $\sigma$ value of the substituents $\left(\sigma_{1}+\sigma_{2}\right)$ is shown in Figure 1 . The plots give a fairly good linear relationship with a $\rho$ of 0.56 .

The polymerization of MMA with $\alpha$-phenylbenzoin as one component in the initiator system was carried out. The rate of polymerization with this system decreased in comparison with that by the $\mathrm{BN}-\mathrm{Py}-\mathrm{CCl}_{4}$ system as shown in Figure 2.

Amine Effect. It is well known that the ability of complex formation of amine with carbon

Table I. Polymerization of MMA by the subBN-Py-CCl $l_{4}$ system

\begin{tabular}{|c|c|c|c|c|c|}
\hline \multicolumn{2}{|c|}{$\mathrm{R}-\mathrm{C}_{6} \mathrm{H}_{5}-\mathrm{C}-\mathrm{CH}-\mathrm{C}_{6} \mathrm{H}_{5}-\mathrm{R}^{\prime}$} & \multicolumn{4}{|c|}{ Conversion, $\% / 3 \mathrm{hr}^{\mathrm{a}}$} \\
\hline & \multicolumn{4}{|c|}{ Initiator system } \\
\hline $\mathrm{R}$ & $\mathbf{R}^{\prime}$ & subBN & subBN-CCl ${ }_{4}$ & subBN-Py & subBN-Py-CCl \\
\hline $\mathrm{H}$ & $\mathrm{H}^{\mathrm{b}}$ & 1.7 & 1.8 & 3.3 & 9.0 \\
\hline $\mathrm{CH}_{3} \mathrm{O}$ & $\mathrm{H}^{\mathrm{b}}$ & 1.2 & 2.3 & 5.2 & 8.4 \\
\hline $\mathrm{CH}_{3}$ & $\mathrm{CH}_{3} \mathrm{~b}$ & 0.8 & 1.0 & 2.2 & 6.7 \\
\hline $\mathrm{CH}_{3} \mathrm{O}$ & $\mathrm{CH}_{3} \mathrm{O}^{\mathrm{b}}$ & 2.2 & 1.6 & 5.4 & 6.8 \\
\hline $\mathrm{H}$ & $\mathrm{H}^{\mathrm{c}}$ & 0.8 & 0.9 & 1.2 & 4.0 \\
\hline$\left(\mathrm{CH}_{3}\right)_{2} \mathrm{~N}$ & $\mathrm{H}^{\mathrm{c}}$ & 0.3 & 0.4 & 0.2 & 1.6 \\
\hline$\left(\mathrm{CH}_{3}\right)_{2} \mathrm{~N}$ & $\mathrm{Cl}^{\mathrm{e}}$ & 0.1 & 0.4 & 1.3 & 2.9 \\
\hline $\mathrm{Cl}$ & $\mathrm{Cl}^{\mathrm{c}}$ & 1.6 & 0.8 & 1.8 & 8.4 \\
\hline
\end{tabular}

a Total conversion.

b [subBN], $4 \times 10^{-2} \mathrm{~mol} / l ;$ [Py], $1.95 \mathrm{~mol} / l ;\left[\mathrm{CCl}_{4}\right], 0.17 \mathrm{~mol} / l$.

c [subBN], $4 \times 10^{-3} \mathrm{~mol} / l ;[\mathrm{Py}], 1.95 \mathrm{~mol} / l ;\left[\mathrm{CCl}_{4}\right], 0.17 \mathrm{~mol} / l ; \mathrm{MMA}, 5 \mathrm{ml}$; temp, $60^{\circ} \mathrm{C}$. 


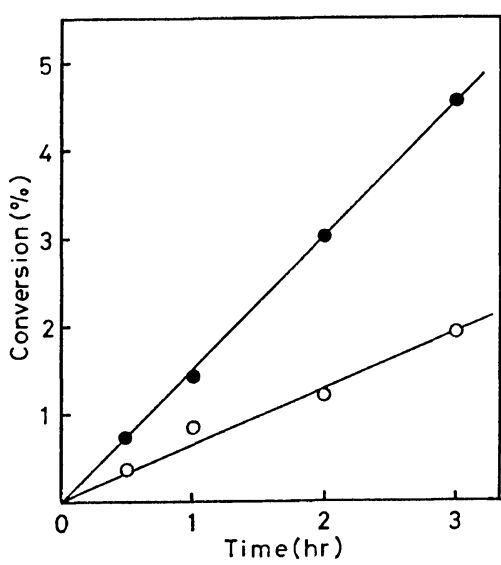

Figure 2. The comparison of the rate of polymerization with initiator system of benzoin and $\alpha$-phenylbenzoin in the presence of a constant concentration of pyridine and carbon tetracholoride: (O), $[\mathrm{BN}], 1 \times 10^{-2} \mathrm{~mol} / l ;(O)$, [ $\alpha$-phenylbenzoin], $1 \times 10^{-2} \mathrm{~mol} / l ; \quad[\mathrm{Py}], 1.98 \mathrm{~mol} / l ;\left[\mathrm{CCl}_{4}\right]$, $0.17 \mathrm{~mol} / l ;\left[\mathrm{M}_{0}\right], 5 \mathrm{ml} ;$ temp, $60^{\circ} \mathrm{C}$. tetrachloride is affected by the basicity and steric effect of amines. The polymerization of MMA by the $\mathrm{BN}-$ subPy $-\mathrm{CCl}_{4}$ system was carried out. As Table II shows, the rate of polymerization by $\beta$-picoline or $\gamma$-picoline as one component of initiator system is faster than that of pyridine, depending on the basicity of amine, whereas $\alpha$ substituted pyridine such as 2,6-lutidine or 2,4,6collidine has less effect for initiating the polymerization than the pyridine does. These results show that the rate of polymerization is more dependent on the steric effect rather than the basicity. Shape and Walker ${ }^{7}$ have reported that the extent of interaction of substituted pyridine at $\alpha$-position with carbon tetrachloride is considerably less than that of pyridine, and depends on the steric effects. Table III shows the results of polymerization by the $\mathrm{BN}-\mathrm{Amine}-\mathrm{CCl}_{4}$ system, together with the basicity of amine. The relative initiating activities of these initiator systems varied greatly according to the amine

Table II. The rate of polymerization of MMA by the $\mathrm{BN}-\mathrm{subPy}-\mathrm{CCl}_{4}$ system

\begin{tabular}{ccclcc}
\hline subPy & $\mathrm{p} K_{\mathrm{a}}$ & $\begin{array}{c}R_{\mathrm{p}} \times 10^{5}, \\
\mathrm{~mol} / l \mathrm{sec}\end{array}$ & \multicolumn{1}{c}{ subPy } & $\mathrm{p} K_{\mathrm{a}}$ & $\begin{array}{c}R_{\mathrm{p}} \times 10^{5}, \\
\mathrm{~mol} / l \mathrm{sec}\end{array}$ \\
\hline Pyridine & 5.45 & 3.8 & 2,4 -Lutidine & 6.45 & 1.8 \\
$\alpha$-Picoline & 5.66 & 3.0 & 2,6 -Lutidine & 6.68 & 0.8 \\
$\beta$-Picoline & 5.53 & 8.7 & $2,4,6$-Collidine & 6.82 & 0.9 \\
$\gamma$-Picoline & 5.88 & 14.3 & & & \\
\hline
\end{tabular}

[BN], $2.8 \times 10^{-2} \mathrm{~mol} / l ;$ [subPy], $0.2 \mathrm{~mol} / l ;\left[\mathrm{CCl}_{4}\right], 0.17 \mathrm{~mol} / l ; \mathrm{MMA}, 5 \mathrm{ml} ;$ temp, $60^{\circ} \mathrm{C}$.

Table III. Polymerization of MMA by the $\mathrm{BN}-\mathrm{Amine}_{-} \mathrm{CCl}_{4}$ system

\begin{tabular}{|c|c|c|c|c|c|}
\hline \multirow{2}{*}{ Amine } & \multicolumn{3}{|c|}{ Relation } & \multicolumn{2}{|c|}{ Conversion, $\%^{\mathrm{a}}$} \\
\hline & $\mathrm{p} K_{\mathrm{a}}$ & Time, hr & Amine $-\mathrm{CCl}_{4}$ & BN-Amine & $\mathrm{BN}-$ Amine $-\mathrm{CCl}_{4}$ \\
\hline Diethylamine & 10.98 & 1 & Trace & 1.2 & 12.5 \\
\hline Triethylamine & 10.65 & 5 & 0.7 & 1.4 & 3.1 \\
\hline$n$-Butylamine & 10.60 & 1 & 0.4 & 1.2 & 38.3 \\
\hline sec-Butylamine & 10.56 & 1 & 0.3 & 1.9 & 31.4 \\
\hline tert-Butylamine & 10.68 & 1 & 0.3 & 1.6 & 7.1 \\
\hline Isobutylamine & 10.43 & 1 & Trace & 1.0 & 24.8 \\
\hline Ethanolamine & 9.50 & 1 & 0.4 & 1.8 & 22.5 \\
\hline Diethanolamine & 9.01 & 1 & Trace & 0.5 & 15.0 \\
\hline Triethanolamine & 7.78 & 1 & Trace & 1.8 & 10.0 \\
\hline Aniline & 4.60 & 3 & - & 0.8 & 2.1 \\
\hline$N$-Methylamine & 4.85 & 6 & - & 1.7 & 3.5 \\
\hline$N, N$-Dimethylamine & 5.06 & 6 & - & 3.2 & 4.0 \\
\hline
\end{tabular}

a Total conversion.

[BN], $4 \times 10^{-2} \mathrm{~mol} / l ;$ [Amine], $0.5 \mathrm{~mol} / l ;\left[\mathrm{CCl}_{4}\right], 0.17 \mathrm{~mol} / l ; \mathrm{MMA}, 5 \mathrm{ml}$; temp, $60^{\circ} \mathrm{C}$. 
Table IV. Solvent effect on the rate of polymerization of MMA by the $\mathrm{BN}-\mathrm{Py}-\mathrm{CCl}_{4}$ system

\begin{tabular}{lcccc}
\hline \multirow{2}{*}{ Solvent } & \multicolumn{2}{c}{$R_{\mathrm{p}}$} & & \\
\cline { 2 - 3 } & \multicolumn{2}{c}{ Initiator system } & \multirow{2}{*}{$\begin{array}{c}\text { Dielectric } \\
\text { constant }\end{array}$} & $\begin{array}{c}\text { Donor } \\
\text { number }\end{array}$ \\
\cline { 2 - 3 } & $\begin{array}{c}\mathrm{Py}-\mathrm{CCl}_{4}, \\
0^{6} \mathrm{~mol} / l \mathrm{sec}\end{array}$ & $\begin{array}{c}\mathrm{BN}-\mathrm{Py}-\mathrm{CCl}_{4}, \\
10^{5} \mathrm{~mol} / l \mathrm{sec}\end{array}$ & & \\
\hline Benzene & 2.2 & 3.4 & 2.27 & 4.9 \\
Dichloromethane & 0.6 & 3.0 & 9.08 & - \\
Acetonitrile & 0.1 & 3.1 & $37.5^{\mathrm{c}}$ & 14.1 \\
Tetrahydrofuran & 2.6 & 4.3 & 7.58 & 20.0 \\
Dimethylformamide & 0.3 & 5.0 & 36.71 & 26.6 \\
Dioxane & & 6.0 & 2.2 & 28.2 \\
\hline
\end{tabular}

a S. L. Murov, "Handbook of Photochemistry," Marcel Dekker, Inc., New York, 1973, p 85. Dielectric constant at $25^{\circ} \mathrm{C}$ unless otherwise noted.

b See ref 9 .

c $20^{\circ} \mathrm{C}$.

$[\mathrm{BN}], 1.6 \times 10^{-2} \mathrm{~mol} / l ;[\mathrm{Py}], 1.2 \mathrm{~mol} / l ;\left[\mathrm{CCl}_{4}\right], 0.1 \mathrm{~mol} / l ; \mathrm{MMA}, 5 \mathrm{~m} l$; solvent, $2 \mathrm{~m} l ;$ temp, $60^{\circ} \mathrm{C}$.

used. The rate of polymerization has a tendency to increase with the basicity of amine. However, in spite of having a similar value to $\mathrm{p} K_{\mathrm{a}}$, the initiating activity of butylamines increased in the following order; primary $>$ secondary $>$ tertiary amine. This order reflects again an increase in the steric factor of amine.

Solvent Effect. The formation of a chargetransfer complex is affected by solvent. As shown in Table IV, the effect of solvent on the rate of polymerization is remarkable.

\section{DISCUSSION}

In our previous paper, ${ }^{6}$ we proposed the following mechanism: a complex is formed between pyridine and carbon tetrachloride, and then the complex reacts with benzoin to give the primary radical, trichloromethyl radical. However, it is well known that benzoin reacts with amine to give the desoxybenzoin derivative. Recently, Takemoto, et al., ${ }^{2,3}$ have reported that in the polymerization of vinyl monomer initiated by $\mathrm{Cu}(\mathrm{II})$ complex-amine-carbon tetrachloride, carbon tetrachloride does not participate in the formation of primary radical in the following manner.

$$
\begin{aligned}
& \mathrm{Cu}(\mathrm{II}) \text { complex }+\mathrm{RCH}_{2} \mathrm{NH}_{2} \\
& \longrightarrow \mathrm{Cu}(\mathrm{I}) \text { complex }+\mathrm{RCH}_{2} \dot{\mathrm{NH}} \\
& \mathrm{RCH}_{2} \dot{\mathrm{NH}}+\mathrm{CCl}_{4} \longrightarrow \cdot \mathrm{CCl}_{3} \\
& \cdot \mathrm{CCl}_{3}+\text { Monomer } \longrightarrow \text { Polymer }
\end{aligned}
$$

According to these results, there is the possibility of an interaction between benzoin and pyridine in the initiation reaction. If so, in the subBNPy system the rate of polymerization by benzoin with electron-withdrawing substituent would be faster than that with electron-donating group. However, Table I shows the opposite results. The interaction between benzoin and pyridine seems unlikely in the primary step, although no simple explanation for the mechanism of initiation in this system can be offered at the present time.

The effects of substituted pyridine on the rate of polymerization seem to be consistent with the ease of the formation of a charge-transfer complex as reported by Shape and Walker. ${ }^{7}$ Similar results were obtained for the other case of amines. Therefore, it is thought that the formation of charge-transfer complex between pyridine and carbon tetrachloride occurs in the initial step. Smith, et al., ${ }^{4}$ has proposed that the copper acetate-catalyzed reaction between amine and carbon tetrachloride proceeds via a formation of charge-transfer complex in the primary step.

Unsymmetrical benzoin can exist in two isomers differing in the relative position of carbinol and carbonyl groups, and enolization presents a route for an isomerization. In the benzoinenediol equilibrium, a basic condition would be expected to favor enediol. Since the Hammett plot gave a straight line in spite of having 
Polymerization of Methyl Methacrylate<smiles></smiles>

[I]

[II]

[III]

different substituent groups at the $4^{\prime}$-position in benzoin, it is reasonable to assume that enediol participates in the initiation reaction. This is supported by the fact that $\alpha$-phenylbenzoin which cannot form enediol has less effect for initiating polymerization. From the positive value of $\rho$, 0.56 , it was clear that the reactivity of substituted benzoin to the charge-transfer complex increased with an increase in electron-withdrawing nature of the substituents.

In our previous paper, ${ }^{6}$ we reported that one mole of each component except the monomer participates in the initiation, reaction and benzil, chloroform and chloride ion were detected. On the basis of these results, the initiation mechanism is written as follows.

$$
\begin{aligned}
& \mathbb{N}_{\mathrm{N}}^{\mathrm{N}}+\mathrm{CCl}_{4} \rightleftharpoons\left[\mathbb{N}_{\mathrm{N}}^{=\mathrm{N}} \cdot \mathrm{CCl}_{4}\right]
\end{aligned}
$$

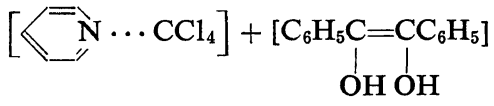

$$
\begin{aligned}
& \longrightarrow \cdot \mathrm{CCl}_{3}+\ll=\mathrm{N} \mathrm{HCl} \\
& \begin{array}{cccc}
+\mathrm{C}_{6} \mathrm{H}_{5} \mathrm{C}-\dot{\mathrm{C}}-\mathrm{C}_{6} \mathrm{H}_{5} & \text { or } \mathrm{C}_{6} \mathrm{H}_{5} \mathrm{C}-\mathrm{CH}-\mathrm{C}_{6} \mathrm{H}_{5} \\
\| & \mathrm{O}_{\mathrm{OH}} & \text { O } & \text { O. }
\end{array} \\
& \text {. } \mathrm{CCl}_{3}+\mathrm{MMA} \longrightarrow \text { Polymer }
\end{aligned}
$$

The benzoin radical formed seems to initiate the polymerization of MMA as minor process.

The initiation and termination of radical polymerization has been shown to be influenced by the nature of the solvent. ${ }^{8}$ Further, the effect on the termination reaction has been found to be attributable to the viscosities of the solvents. The viscosities of the solvents used in this study fall into a small range $\left(0.38-0.54 \mathrm{cp}\right.$ at $\left.60^{\circ} \mathrm{C}\right)$. The large solvent effect on the polymerization with this system shows that the solvent affects the initiation reaction in either the formation of the complex or the decomposition of the complex with benzoin. The rates of polymeri- zation of MMA with $\mathrm{Py}-\mathrm{CCl}_{4}$ system have a tendency to increase with a decrease in the dielectric constant, which is related by the ease of formation of charge-transfer complex. The erizatpolymion of MMA with three-component system is correlated with the donor number of solvent. ${ }^{9}$ Therefore it is thought that the solvent participates in the interaction between benzoin and the charge-transfer complex. However, the detail of this solvent effect remains unclear.

In the case of primary or secondary amine, it is possible to react amine with benzoin to give desoxybenzoin derivatives. The initiation mechanism of polymerization of MMA with benzoin and carbon tetrachloride in the presence of primary or secondary amine might be different from the case of tertiary amine. Further details of these reaction will be reported together with the results of solvent effects.

\section{REFERENCES}

1. W. J. Lautenberger, E. N. Jones, and J.G. Miller, J. Am. Chem. Soc., 90, 1110 (1968), and references therein.

2. Y. Inaki, M. Ishiyama, and $\mathrm{K}$. Takemoto, Makromol. Chem., 160, 127 (1972).

3. Y. Inaki, M. Ishiyama, and K. Takemoto, Angew. Makromol. Chem., 27, 175 (1972).

4. J. R. L. Smith and Z. A. Malik, J., Chem. Soc., Sect. B, 920 (1970).

5. J. Ukita, Kobunshi Kagaku (Chem. High Polymers), 10, 358 (1953).

6. K. Inoue, N. Nakagawa, and T. Tanigaki, Polym. J., 8, 254 (1976).

7. A. N. Shape and S. Walker, J. Chem. Soc. Sect. B, 157 (1962).

8. A. M. North and G. A. Reed, Trans. Faraday Soc., 57, 859 (1961).

9. V. Gutmann, "Coordination Chemistry in NonAqueous Solutions," Springer-Verlag, Berlin, (1968). 